\title{
Financial Records Management System for Micro Enterprise
}

\author{
Yeow Xin Yin", Nureize Arbaiy" Jamilah Din* \\ \# Faculty of Computer Science and Information Technology, University Tun Hussein Onn Malaysia, Malaysia \\ * Faculty of Computer Science and Information Technology, Universiti Putra Malaysia, Malaysia \\ E-mail:di140005@siswa.uthm.edu.my,nureize@uthm.edu.my,jamilah@upm.edu.my
}

\begin{abstract}
Financial records represent a formal records or written reports of financial activities of an entity to quantify financial performance and financial strength. Most of micro enterprises under Centre for Business and Entrepreneurship (CBER) UTHM is currently using manual records bookkeeping system to keep the financial records. This cause time consuming and human errors. Hence, financial records management system for micro enterprises under CBER is developed. This system is able to simplify invoice records and quotation collection. Financial records management system also can eliminate accounting errors and minimizing records keeping redundancy. The system is developed by using software Brackets, Xampp and PHP programming through agile methodology guide. This system is expected to help micro enterprises to keep track and manage financial records efficiently.
\end{abstract}

Keywords — Financial records, manual bookkeeping, management system, microenterprise.

\section{INTRODUCTION}

Financial records management system is the methodology and software allow micro enterprises to oversee and govern their businesses' assets, incomes and expenses with their business objectives of maximizing profits and ensuring sustainability [1]. Furthermore, financial records management system is beneficial for micro enterprises to improve their short or long-term business performance [2], [11] by simplify invoice records and expenses collection to eliminating accounting data errors due to human data entry and minimizing records keeping redundancy. Various micro enterprises have their own financial records system such as manual records bookkeeping or stand-alone records system.

Using such traditional system requires Micro enterprises to improve and streamline their financial records process become more technology efficient and time saving. Numerous Micro enterprises are currently using manual bookkeeping records. Current implementation on manual records system had bring many major problems in records management such as data loss, searching problem, and data redundancy. The implementation of manual records system is also slow, resulting inefficient invoice processing which make them difficult to keep tract of cash flow and maximize their businesses profits. Paper-based processes on manual records system are time-consuming in manual data entry which is expensive and potential for human error [2]. This situation may lead to poor document processing and inefficiencies.

Thus, web-based Financial Records Management System for Micro Enterprises (FRS-ME) is developed to provide timely and accurate information in their records management in monitoring cash flow and financial performance. Micro enterprises which still using manual records system is recommended to implement Financial Records Management System (FRS-ME) to assist and well manage their financial records in good governance through online system. FRS-ME is an efficient and effective financial management system enables micro enterprise owners to view online invoice, quotation statement in their system records. The objectives of this project are to design a system's processes and database, and develop Financial Records Management System for micro enterprises (FRS-ME).

The users for the system are enterprise administrator and client. Micro enterprise administrator can review their business' records report through system to plan their future implications. Micro enterprise administrator also able to manage their records which can create new invoice records, new quotation records, view reports, read history, update records details, and remove data in the system where necessary. Meanwhile, clients are also able to receive quote order from enterprise administrator and able to view their financial invoice records as well as view the payment method they made.

The main modules of system are user's registration and authentication, cash flow management, evaluation financial records and financial records report. The main modules of system are system login, manage user profile, managing enterprise's product, managing client's profile, quotation records management, invoice records management, managing payment and generate report. Functional development of system consists micro enterprise administrator can view 
dashboard by login to system and generate reports to monitor micro enterprises' business performances and current payment status in real time. Besides, micro enterprises administrator can edit their profile details, add product details, update the product information, add clients' information, check payment status, generate report and manage quotation and invoice records. Furthermore, micro enterprises administrator will register client id and password for them to allow all clients to check the incoming and outgoing payments and records to be viewed after report is generated. Additionally, client is able to view the quotation order send by enterprise administrator and view the paid and unpaid invoice as well as payment method they made which manage in this section.

This report consists of several parts. Part II sets out the review of the literature. Part III describes the methodology of the system. Part IV describes the analysis and design of systems. Part V describes system implementation and testing. Part VI describe the conclusion.

\section{RELATED WORKS}

Financial Records Management System (FRS) is an important tool to help management team and board members in managing collective financial resources more efficiency and profitably [12 - 13]. Most businesses use to simplify records keeping and produce meaningful and accurate reports. Advantages of online financial records management system (FRS) help organizations to record business transaction including income, expenses and assets details. It is an efficient way to keep financial records and requires less storage space. Online FRS is able to increase the productivity, accurate in no routine work, high speed, flexibility of reporting, reliability, easy to back up and restoration of records. FRS enable users generate invoices, financial statement compares of using handwriting records technique in an easier way. FRS allows users to back up records and keep them in a safe place in case of fire or theft. Therefore, an online financial records management system for micro enterprises (FRS-ME) is developed to in this project to help micro enterprises to keep track and manage financial records efficiently.

\section{Reviews on Existing System}

There are three existing financial records systems were investigated which are Sage User Business System (UBS)[4] - [5], JomSales Business Management System [6] and Zasio Enterprise Records and Document Management System [7].

\section{i. $\quad$ Sage User Business System (UBS)}

Sage User Business System (UBS) is developed by a financial services company in Swiss. UBS is suitable for small and medium enterprises organizations in Malaysia. UBS is a stand-alone system which only limited using by organizations purchase of this system. Features provided by UBS is enable companies to work easier and more efficiently to generate general ledger, debtors, creditors and assets register. UBS is focus on payroll and wider human resources function in its system instead of records reports. In addition, UBS is sometimes in possession of dated technology need for updating the system only users can continuously use for their system. It is a content management system which deliver multi-channel customer experiences in business. UBS uses C\# as developing programming language. It used personal computer as a stand -alone hardware to run the local applications on its own.

\section{ii. JomSales Business Management System}

JomSales Business Management System is cloud-based integrated software which is developed especially for small business organizations to generate business documents and monitor cash flow. It is only special designed for small business organizations to optimize small business operations. JomSales Business Management System is more focus on invoicing. JomSales enable users to create and sending sale document. Technology used by JomSales Programming languages used by system developer is JavaScript which consists jQuery, Easing, jQuery Cookie and jQuery Masonry. jQuery Easing is an extension that provides functionality to easy make things run on screen. jQuery Cookie is a simple, lightweight jQuery plugin for reading, deleting and writing cookie. jQuery Masonry is a layout plugin for jQuery as the flip side of CSS floats.

\section{iii. Zasio Enterprise Records and Document Management System}

Zasio Enterprise Records and Document Management System is an information governance company provides affordable technology solutions and consulting services to organization across the globe. Zasio Enterprise Records and Document Management System offers first rate knowledge and experience to help organization plan and support records management then convert data to customer so that they know the planning result. Zasio uses WordPress as a state of the art semantic personal publishing platform with a focus on aesthetics and web standard. The programming language used by Zasio is PHP which is widely used as general-purpose scripting language that is especially suited for Web development and can be embedded into HTML.

\section{METHODOLOGY}

This section explains methodology employed in the development of this project which is based on Agile model [1] and the activities that had been carried out in each phase. Agile model [7] is a flexible methodology method to better fit in a fast-changing environment. Every iteration occurs in agile model involves cross functional team working simultaneously on various areas such as planning, analysis requirements, design, coding, unit testing and acceptance testing [8] - [10]. A system prototype should be delivered at the end of iteration.

Table 1.0 shows the system development workflow in this project. System development workflow is based on project structure model used by this project which is Agile model in SDLC methodologies.

TABLE 1

SYSTEM DEVELOPMENT WORKFLOW

\begin{tabular}{|l|l|l|}
\hline Phase & Activity & Deliverables \\
\hline Planning & - Task scheduling & $\begin{array}{l}\text { - Gantt chart } \\
\text { - Proposal }\end{array}$ \\
\hline
\end{tabular}




\begin{tabular}{|l|l|l|}
\hline & $\begin{array}{l}\text { - Determine project background, } \\
\text { problem statement, objective, } \\
\text { scope and project significant }\end{array}$ & \\
\hline Analysis & $\begin{array}{l}\text { - Requirement identification } \\
\text { - Find the ideal on result get from } \\
\text { propose system } \\
\text { - Analyzing company's } \\
\text { management, workflow, financial } \\
\text { records procedures and its data } \\
\text { processing process }\end{array}$ & $\begin{array}{l}\text { - Data Flow } \\
\text { Diagram (DFD) } \\
\text { Level 0 } \\
\text { - Data Flow } \\
\text { Devel 1 } \\
\text { - Entity } \\
\text { Relationship } \\
\text { Diagram }\end{array}$ \\
\hline Design & $\begin{array}{l}\text { - Understand the system } \\
\text { requirements } \\
\text { - Create a blueprint for system and } \\
\text { users interfaces }\end{array}$ & $\begin{array}{l}\text { Application } \\
\text { menu structure } \\
\text { design }\end{array}$ \\
\hline Coding and & $\begin{array}{l}\text { - Write coding according system } \\
\text { functionalities } \\
\text { - System testing }\end{array}$ & $\begin{array}{l}\text { Identify any } \\
\text { failures or errors }\end{array}$ \\
\hline Testing & $\begin{array}{l}\text { - Installed, run and used by users } \\
\text { and company staffs } \\
\text { - Update the propose system } \\
\text { acceptance } \\
\text { - Deployment of system from users }\end{array}$ & $\begin{array}{l}\text { - Propose system } \\
\text { acceptance result } \\
\text { - Deployment of } \\
\text { system result }\end{array}$ \\
\hline Implementation
\end{tabular}

\section{SYSTEM DESIGN}

System analysis is carried out to meet users' requirements by collecting data and information to develop the proposed system. During the analysis phase, the system requirement of Financial Records Management System for Micro Enterprises (FRS-ME) under CBER will be gathering. Analysis model development will be carried out using context diagram, Data Flow Diagram (DFD) and Entity Relationship Diagram (ERD) is drawn to represent the process model and provide a clear visualization of the proposed system.

Design phase involves defining the system architecture to illustrate the work flow of the developed system. System design is constructed with all information that were obtained earlier. The main goal of this stage is to convert a set of complete and detailed specifications will be used during next phase of previously defined needs in developing proposed FRS-ME. Structured approach is selected to perform analysis and design of FRS-ME. Fig 1 illustrates context diagram for this system.

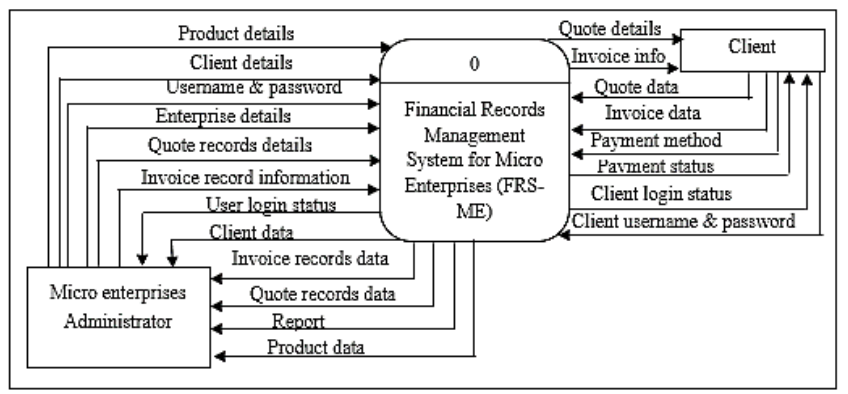

Fig 1 Context Diagram

There are two entities involved in the developed system which are enterprises administrator and client. Enterprise administrator are allowed to login to system to manage financial records information and search records history which are stored in the database. Client is able to view their quote orders and invoice records information records through system. All users are required to present username and password to login to the system. Username is needed to identify whether there are an existing username in system to pass through the verification process.

The entity relationship diagram for Financial Records Management System for Micro Enterprises (FRS-ME) is depicted in Fig 2. Each entity has its own characteristics including different unique keys and foreign keys that distinguish between all participating entities.

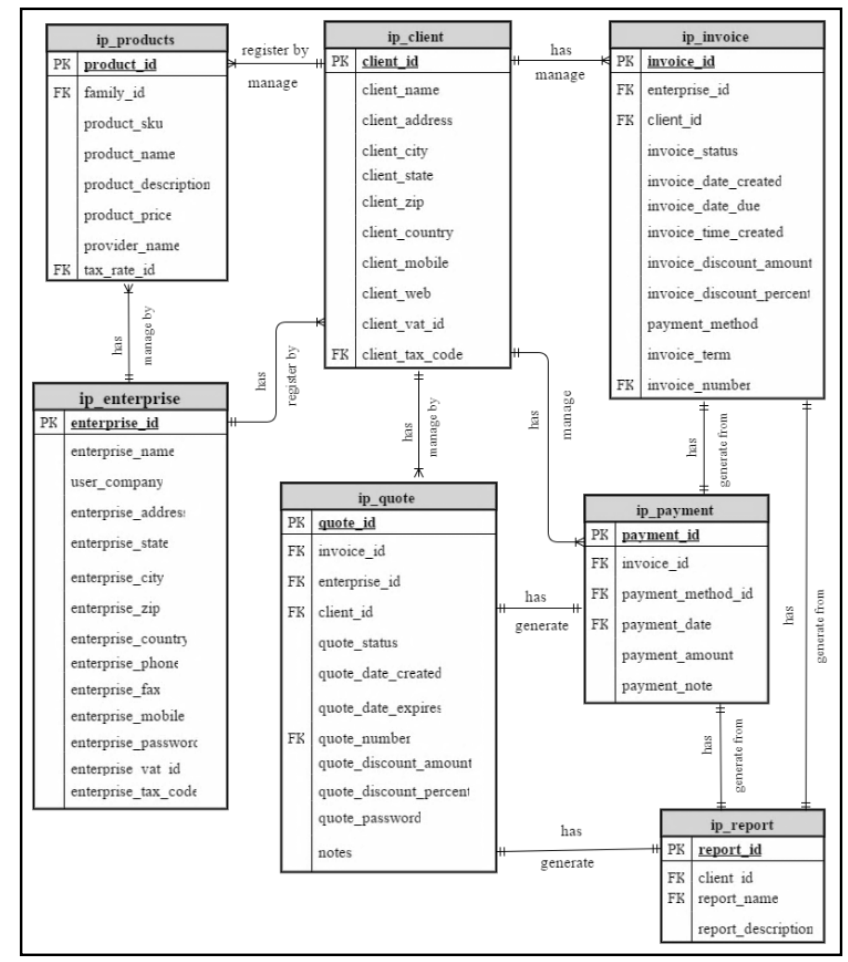

Fig 2 Entity Relationship Diagram (ERD)

\section{RESULTS AND DISCUSSION}

A login function was used to ensure system users from different categories to reach specified modules based on each respective user's role. Username and password are compulsory provided by users for login. According to Fig 3, a series of validation will be done on users' input for checking on password length and function login user () is used to check whether the username as email address provided have been registered. Then, the login function is invoked to perform the login process. User will be directed to either user page or admin page based on account privilege.

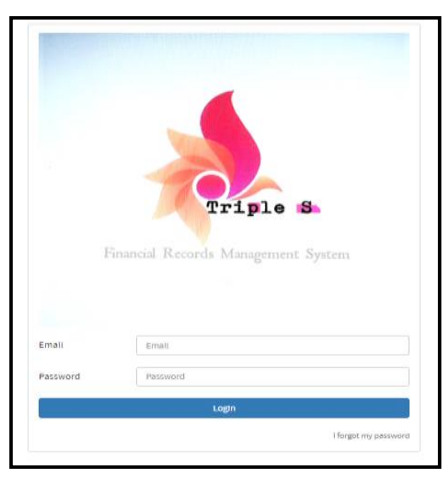

Fig 3 Login interface 
Financial Records Management System for micro enterprise (FRS-ME) enable enterprise administrator to fill in enterprise details in Enterprise Profile Module. Enterprise Profile Module consists of corporate profile information in details. Enterprise administrator is able to edit and update their profile information where necessary. Fig 4 shows Enterprise Profile Management Module.

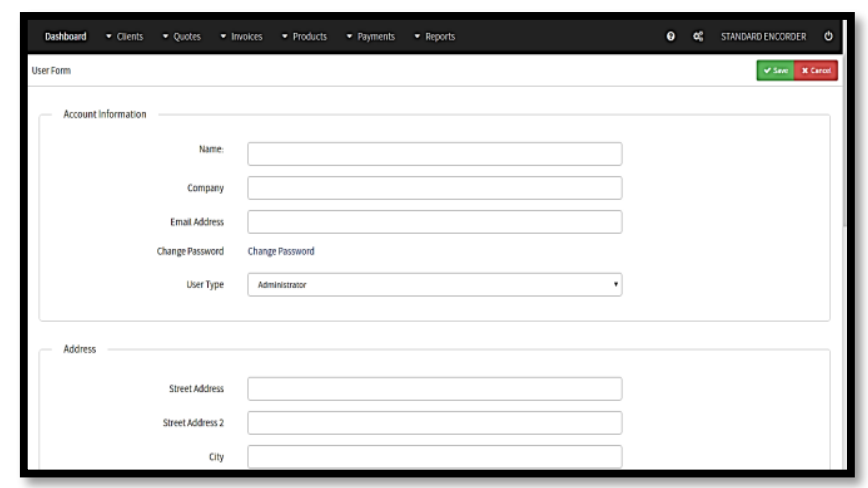

Fig 4 Enterprise Profile Management Module

Product represent the catalogue of items or goods sold by enterprise. Enterprise administrator is able to register new product details in the product form as shown in Fig 5. The new product can be registered by providing a product name, product description, product price and the product tax rate.

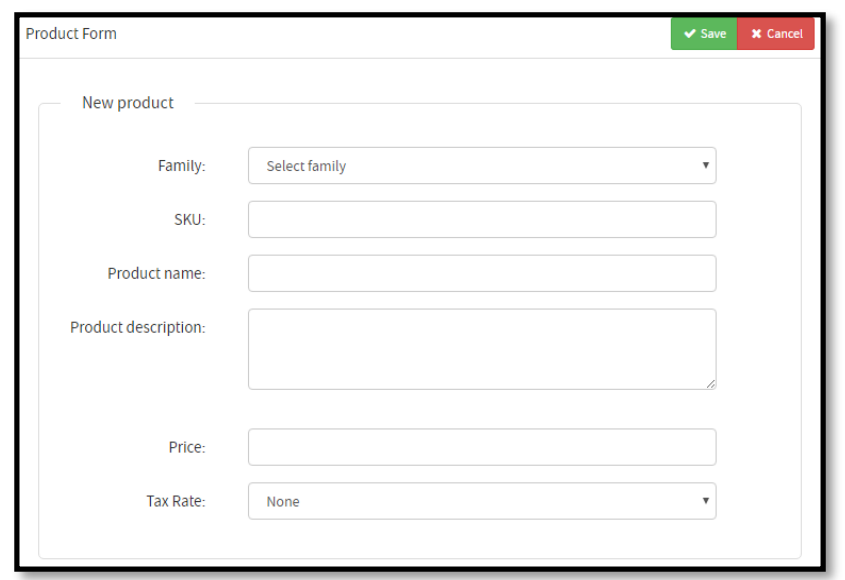

Fig 5 Product Management Module interface

Fig. 6 shows the Quote Records Management Module on adding a new quote record. In this process, micro enterprise administrator is able to add new quote records into system. The existing quote records can be viewed by enterprise administrator and generate report from quotation database. Besides, enterprise administrator also able to delete existing quote records from system. Clients can view quotation records by entering quotation records date and delete quote order from system.

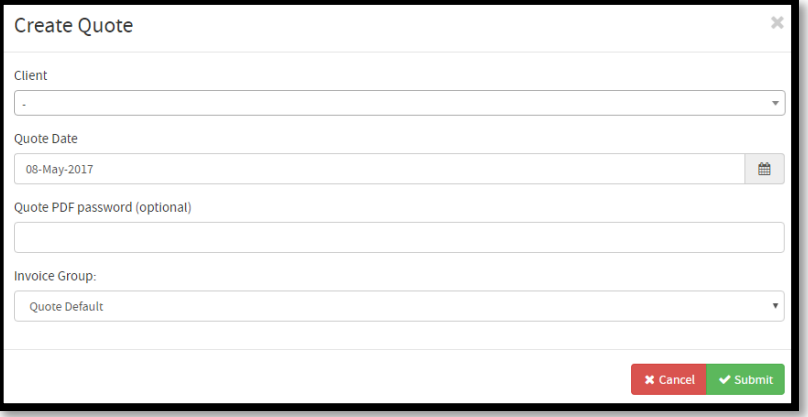

Fig 6 Quote Records Management Module

An invoice is a list of services rendered to client which containing prices and charges. FRS-ME provides invoice creation function which contains feature such as client name and invoice date which it was issued. Enterprise administrator is able to modify an invoice if necessary. Fig. 7 shows the Invoice Management interface of creating a new invoice record.

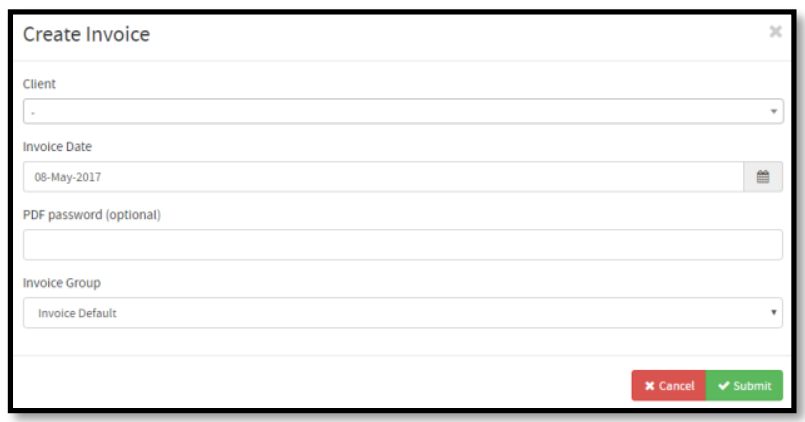

Fig 7 Invoice Management interface of creating a new invoice record

Fig 8 demonstrates that the system enables both system user to manage payment method for invoice. Enterprise administrator will select the invoice payment method through system and client will received the payment method selected by enterprise administrator after login into system. Client is able to verify the payment method made by selecting approve or reject function once the invoice payment status had been updated.

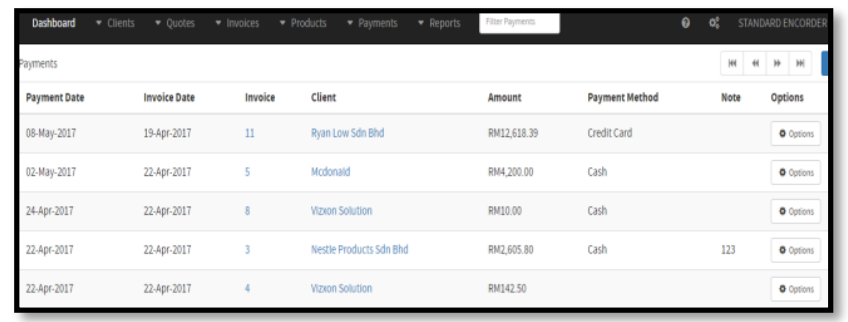

Fig 8 Payment Management Module

Fig. 9 shows the system provides a flexible report generation functionality for system users which allow them to generate financial records report from invoice records, quote records and payment history. 


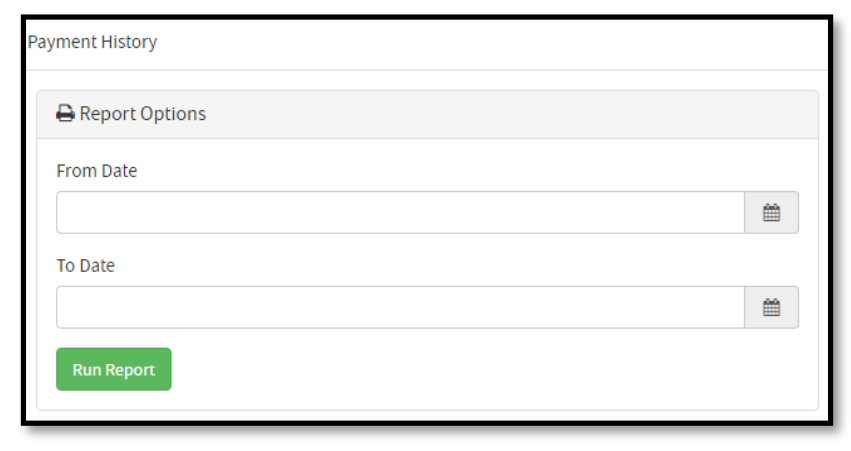

Fig 9 Generate Payment Report Module

\section{CONCLUSIONS}

The development of Financial Record Management System for micro enterprises (FRS-ME) is enable the micro enterprises to track their financial records. The objectives of the proposed system have been achieved in the scope of the financial records management process for micro enterprises. Agile methodology had been applied to develop this system. The final system is built successfully and meet the users' requirement. Besides, the system is an open source for all micro enterprises which encourage more micro enterprises to use the developed online financial record management system. Therefore, with the suggestion taken for the future improvements will develop a better and perfect financial records management system and give massive contributions to them in the future.

\section{ACKNOWLEDGMENT}

The authors would like to thank University Tun Hussein Onn Malaysia for the support and encouragement.

\section{REFERENCES}

[1] R., Allen, R., Hemming, \& B. Potter, (Eds.). The international handbook of public financial management. Springer, 2013.

[2] K. Barata, P. Cain, and D. Routledge. International Records Management Trust Right and Records. London, United Kingdom: Institute London, 2001.

[3] UBS, Financial Service Inc. Accounting Protection 2013

[4] Software UBS. United States: Protection Corporation (SIPC)

[5] JomSales. (2016). JomSales. Retrieved August 16, 2016, from JomSales Business Management System: https://jomsales.com/

[6] Zasio, Enterprise Inc. (2016). Zasio. Retrieved August 8, 2016, from Zasio Enterprise Records and Document Management System: http://www.zasio.com/

[7] J., Highsmith. Adaptive software development: a collaborative approach to managing complex systems. Addison-Wesley, 2013.

[8] D., Turk, R., France, \& B., Rumpe, Assumptions underlying agile software development processes. arXiv preprint arXiv:1409.6610. 2014.

[9] S., Ashmore, \& K. Runyan. Introduction to agile methods. AddisonWesley Professional, 2014.

[10] R., Levy, M., Short, \& P. Measey. Agile foundations: principles, practices and frameworks. BCS. 2015.

[11] McKinney, J. B. (2015). Effective financial management in public and nonprofit agencies. ABC-CLIO.

[12] E. F., Brigham, \& M. C. Ehrhardt. Financial management: Theory \& practice. Cengage Learning, 2013.

[13] J. S. Ang, "Small business uniqueness and the theory of financial management." The Journal of Entrepreneurial Finance, vol. 1(1), 1991. 